\title{
Influence of glycerol and temperature on the rheological properties of potato starch solutions**
}

\author{
Germán Ayala* ${ }^{*}$ Rubén A. Vargas ${ }^{2}$, and Ana C. Agudelo ${ }^{3}$ \\ ${ }^{1}$ Faculty of Animal Science and Food Engineering, University of Săo Paulo, Av. Duque de Caxias Norte 225, \\ 13635-000, Pirassununga, SP, Brazil \\ ${ }^{2}$ Department of Physics, Univalle University, AA 25360, Cali, Colombia \\ ${ }^{3}$ Faculty of Engineering and Administration, National University of Colombia, Palmira campus, AA 237, Colombia
}

Received September 9, 2013; accepted April 16, 2014

\begin{abstract}
A b s r a c t. Effects of temperature and glycerol concentration on rheological properties of potato starch solutions were investigated. The flow behaviour (shear stress against shear rate) was fitted to various models: power law, Herschel-Bulkley, Bingham, modified Bingham and Casson models. However, it was found that the Herschel-Bulkley model describes better the flow behaviour observed at various temperatures and glycerol concentrations, for flow behaviour index values between 0.44 and 0.78 , typical of pseudoplastic solutions. The effect of glycerol concentration on each of the fitting parameters for Herschel-Bulkley model was well modelled by a second-degree polynomial at various temperatures. The simultaneous influence of glycerol concentration and temperature on shear stress could be represented empirically by a seconddegree polynomial function that includes linear coupling between concentration and temperature. Finally, the variation of the consistency coefficient with both temperature and glycerol concentration was well described by an exponential expression, with an activation energy value of $2.78 \mathrm{~kJ} \mathrm{~mol}^{-1}$. The results indicate that both glycerol content and temperature have the effect of diluting potato starch solutions.

Ke y w or d s: glycerol, potato starch solutions, pseudoplastic behaviour, rheological models
\end{abstract}

\section{INTRODUCTION}

Films based on glycerol/starch have been extensively studied as biomaterials with promising application in the food industry as comestible or biodegradable packaging (Bertuzzi et al., 2007; Gennadios et al., 1994; Tapia-Blácido et al., 2007; Tharanathan, 2003). Sothornvit and Krochta

*Corresponding author e-mail: gayalav1230@gmail.com

**This work was financial supported from National University of Colombia, Palmira campus, DIPAL code numbers QUIPU 2010100772, and 2020100626, 2008-2013.
(2001) mentioned the great potential of these films to ensure optimum quality and shelf life. These materials have been used as coatings on minimally processed fruits and vegetables like tomatoes, cucumber, red pepper, apple and mango (Mali and Grossmann, 2003). Other applications of glycerol/ starch films are reported in the non-food industry for the development of solid polymer electrolytes with ionic conduction (Ahmad-Khiar and Arof, 2010; Ayala et al., 2011, 2012a; Caicedo et al., 2010). In cold water, starch is nonsoluble, but when starch solutions are heated above the gelatinization temperature, the viscosity increases due to starch granules losing their crystallinity and absorb large amounts of water (Che et al., 2008). An important step of manufacturing process of films based on starches is the control of the rheological properties of the filmogenic solutions, where the apparent viscosity of starch solutions can be modified by temperature, shear rate, plasticiser type and combinations of these variables. The viscosity modification of starch solutions must be known to ensure safety and improve quality, as well as for the design of equipment and process that require the calculation of heat transfer and pressure drops or modelling of the continuous treatment (Che et al., 2008; Lagarrigue and Alvarez, 2001; Marcotte et al., 2001).

The rheological properties of cassava, corn, potato, tapioca, waxy maize, sweet potato, and sago starch solutions have been investigated in many works, where the rheological behaviour was fitted to the power law model within a temperature range of $20-95^{\circ} \mathrm{C}$ (Chen and Ramaswamy, 1999; Iida et al., 2008; Juszczak et al., 2012; Nurul et al., 1999). The mixture of starch solutions with other compounds such as kaolin, methylcellulose and glycerol 
presents a rheological behaviour that deviates from the power law and is better fitted to the Casson and HerschelBulkley models (Drożdż and Tomaszewska-Ciosk, 2007; Peressini et al., 2003).

Non-existence of rheological data is one of the problems encountered during numerical simulation and equipment design of glycerol/starch solutions. In previous studies, the rheological properties of glycerol/starch solutions were analysed as a function of both temperature and glycerol concentration (Ayala et al., 2013). It was found that these solutions exhibited a pseudoplastic behaviour which was very well fitted to the power law model within the temperature range of $30-70^{\circ} \mathrm{C}$ and glycerol/cassava starch weight fraction up to 0.5 . Moreover, the flow behaviour index $(n)$ did not show significant changes as a function of temperature and glycerol concentration. However, the apparent viscosity and the consistency coefficient $(K)$ showed strong variations with temperature and glycerol content (Ayala et al., 2013). Although the power law model describes well the rheological properties of glycerol/starch solutions, other models proposed in the literature to characterize the pseudoplastic behaviour have not been tested in these systems.

This study aimed to characterise the rheological properties of glycerol/potato starch solutions, reporting a more detailed analysis related to their dependence on temperature and glycerol concentration, and characterizing pseudoplastic fluids.

\section{MATERIALS AND METHODS}

Potato starch (Solanum tuberosum L.) was obtained from potato tubers from a local market in Palmira city (Colombia). The potato starch was isolated following the preparation method reported by Ayala et al. (2012b). Commercial grade glycerol (99\%) was purchased from TC Química (Cali, Colombia).

Chemical characterization of potato starch has been reported previously, this raw material had values as follows: humidity $(12.5 \pm 1.5 \%)$, ash $(0.5 \pm 0.2 \%)$, crude protein $(0.5$ $\pm 0.1 \%)$, crude fat $(0.6 \pm 0.1 \%)$, crude fibre $(0.8 \pm 0.1 \%)$ and carbohydrate contents $(97.6 \pm 0.6 \%)$ (Caicedo et al., 2010). This chemical composition is similar to that reported by Alvani et al. (2011); Alvis et al. (2008) and Perrera et al. (1997).

Glycerol/potato starch (G/PS) solutions at various concentrations were prepared using a methodology reported in previous works (Caicedo et al., 2010; Ayala et al., 2011, 2012a, 2013). Three grams of potato starch were initially gelatinized in $100 \mathrm{ml}$ of water at $85 \pm 1^{\circ} \mathrm{C}$ for 15 min under constant agitation with magnetic stirring at 250 r.p.s. After $15 \mathrm{~min}$, a viscous and transparent solution was obtained. Glycerol was then added in different proportions into identical starch solutions in beakers at $85 \pm 1{ }^{\circ} \mathrm{C}$ and mixed for 15 min under constant agitation at 250 r.p.s. We prepared three glycerol/potato starch concentrations with weight fraction $\mathrm{G} / \mathrm{PS}=0.1,0.3$ and 0.5 , respectively.
The rheological properties of the three G/PS solutions were measured using a viscometer (DV-E Brookfield, Middleboro, MA, USA), starting at $60^{\circ} \mathrm{C}$, then they were measured at three temperatures $\left(30,40\right.$ and $\left.50^{\circ} \mathrm{C}\right)$. The shear stress $(\tau)$ was measured as a function of shear rate $(\dot{\gamma})$ which was increased from 0.02 to $0.33 \mathrm{~s}^{-1}$ using a spindle type S-62. Six hundred millilitres of solution were loaded into the cylindrical cup and cooled in a water bath at specific temperature. All analyses were performed at least three times using the Brookfield viscometer between $20-80 \%$ full torque scales. Data were analysed using MS-Excel software. Values of shear stress as a function of shear rate for the G/PS solutions were fitted to different models: the power law (Eq. (1)), Herschel-Bulkley (Eq. (2)), Bingham (Eq. (3)), modified Bingham (Eq. (4) and Casson (Eq. (5)) models:

$$
\begin{gathered}
\tau=K \dot{\gamma}^{n}, \\
\tau=\tau_{0}+K \dot{\gamma}^{n}, \\
\tau=\tau_{0}+K \dot{\gamma}, \\
\tau=\tau_{0}+K \dot{\gamma}+C \dot{\gamma}^{2}, \\
\tau=(\mathrm{a} \sqrt{\dot{\gamma}}+\sqrt{\mathrm{b}})^{2},
\end{gathered}
$$

where: $\tau_{0}$ is the yield stress $(\mathrm{Pa}), K$ is the consistency coefficient $\left(\mathrm{Pa} \mathrm{s}^{\mathrm{n}}\right), \dot{\gamma}$ is the shear rate, $n$ is the flow behaviour index (dimensionless), a ([Pa s$\left.\left.]^{\mathrm{n}}\right]^{0.5}\right), \mathrm{b}\left([\mathrm{Pa}]^{0.5}\right)$ and $\mathrm{C}(\mathrm{Pa}$ $\left.\left[\mathrm{s}^{\mathrm{n}}\right]^{2}\right)$ are constants.

\section{RESULTS AND DISCUSSION}

Typical flow curves of shear rate $v s$. viscosity for the $\mathrm{G} / \mathrm{PS}=0.1$ solution at different temperatures are shown in Fig. 1, in double logarithmic scale. Non-linear decreasing of viscosity as a function of shear rate indicated a nonNewtonian behaviour (shear-tinning behaviour), typical of pseudoplastic systems, which has been reported in cassava, canna, corn, bore, potato, tapioca, waxy maize, sweet potato starch solutions (Ayala et al., 2012b; Chen and Ramaswamy, 1999; Iida et al., 2008; Juszczak et al., 2012; Nurul et al., 1999), and mixtures of glycerol/cassava starch solutions (Ayala et al., 2013). In a liquid, viscosity is a function of intermolecular forces that restrict molecular motion (Nurul et al., 1999). Therefore, increasing causes a breakdown of amylose and amylopectin fragments in the solutions, induced by the hydrodynamic forces generated during cutting. As a result, the viscosity of the solutions reduced as shown in Fig. 1 (Ayala et al., 2012b; Che et al., 2008). Similar behaviour was observed with increasing temperature (Fig. 1), attributed to the breakdown in the polymer structure and weak interactions, such as hydrogen bonds (Grigelmo et al., 1999). 


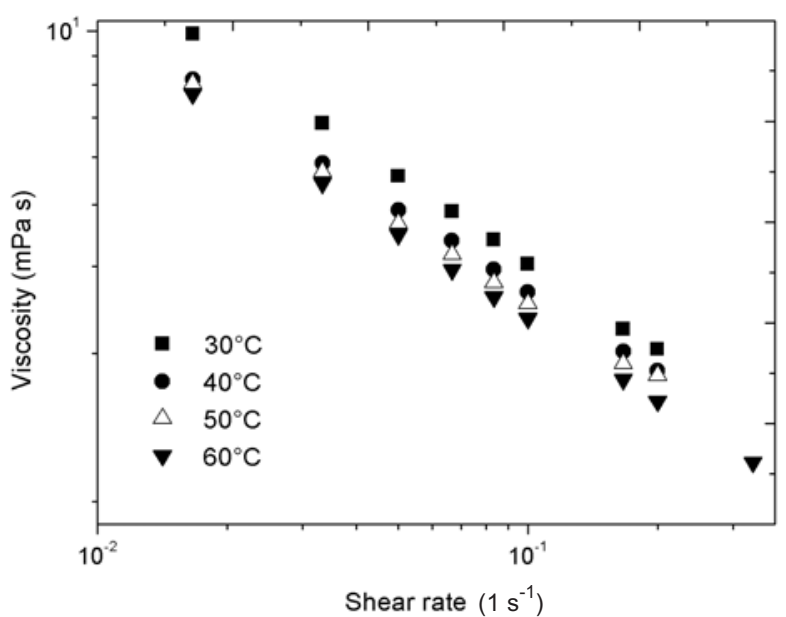

Fig. 1. Viscosity $v s$. shear rate in double logarithmic scale for $\mathrm{G} / \mathrm{PS}=$ 0.1 solution at different temperatures.

Figure 2 shows the flow curves for the G/PS $=0.1,0.3$ and 0.5 solutions, where the shear stress decreased with the glycerol addition. These results are opposite to those reported previously for glycerol/cassava starch solutions (Ayala et al., 2013). One possible hypothesis to explain these results can be based on the water solubility index (WSI). Alvis et al. (2008) reported the WSI for cassava (variety HCM-1) and potato starches cultivated in the south-western of Colombia, obtaining values of $3.67 \pm 0.0$ and $2.97 \pm 0.1$ (w/w in dry basis), respectively, indicating that cassava starch solutions developed a higher viscosity (Alvis et al., 2008). This result was confirmed in a previous work reported by Ayala et al. (2013), in which glycerol/cassava starch (variety HMC-1) solutions showed a range of viscosity between 1.39 and 2.45 Pa s, values which were a function of the shear rate, temperature, glycerol concentration in the solution and the interaction between these variables. In contrast, G/PS solutions showed viscosity values between 0.66 and $9.89 \mathrm{mPa} \mathrm{s}$, which are very small in comparison with those reported for glycerol/cassava starch solutions (Ayala et al., 2013). When cassava starch is gelatinised in water, the starch creates an interaction with the solvent. With glycerol addition into the solutions, cassava starch can still generate more interactions of hydrogen bonds type between starch and glycerol, increasing the viscosity of the solutions. Oppositely, $100 \mathrm{ml}$ of distilled water used in this study saturated all possible interactions that the potato starch could generate ( $3 \mathrm{~g}$ of potato starch), then, the interaction of the hydrogen bonds type is inhibited by the glycerol addition, where the glycerol has an effect of diluting the solution. Chien-Hsien et al. (2009) reported that the use of glycerol in solutions of tapioca starch/ decolourized hsian-tsao gum does not alter the rheological properties in these systems because the glycerol is relatively a very small molecule in comparison with those of tapioca starch and hsian-tsao gum.

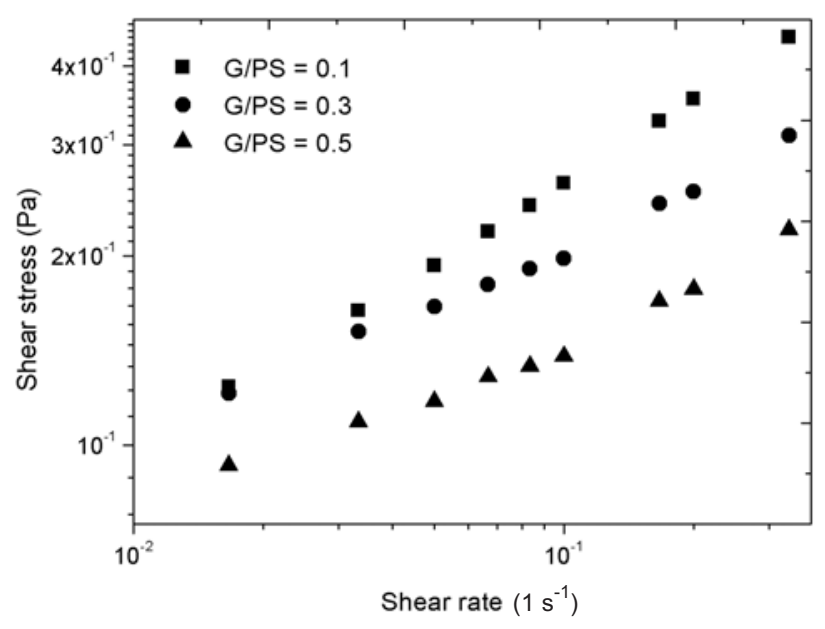

Fig. 2. Flow curves in double logarithmic scale at $30^{\circ} \mathrm{C}$ for $\mathrm{G} / \mathrm{PS}=$ $0.1,0.2$ and 0.3 .

Suitability of different rheological models was tested by fitting the shear stress $v s$. shear rate experimental data to Eqs (1)-(5) based on the least-square analysis. As it can be seen in Table 1, the rheological values for the G/PS solutions can be described using the power law, Herschel-Bulkley, Bingham or Casson model, where the $\mathrm{R}^{2}$ values for all fits were very close to the unity, indicating an excellent fit. Standard deviation calculations of $K, n, \tau_{0}$, a, and b, parameters as a function of temperature and G/PS concentration were rather low, giving dispersion values lower than $7 \%$ of the mean value, thereby, the dispersion of the data for the fit parameters as a function of both temperature and glycerol concentration was not significant. Values for the modified Bingham model are not shown because the $\mathrm{C}$ parameter was equal to zero in all fits, thus it becomes identical to those given by the Bingham model. In comparison, the power law and Herschel-Bulkley are best models to predict the rheological behaviour in G/PS solutions. However, when the shear rate approached zero, the viscosity in G/PS solution increased (Fig. 1), which suggested the existence of parameter in the fits (Rao et al., 1997). Consequently, the Herschel-Bulkley is the more appropriate model to describe the flow behaviour in G/PS solutions under the evaluated conditions of glycerol concentration and temperature.

Grigelmo et al. (1999) reported that if the flow behaviour index is lower than $1.0(n<1)$, the solution presents a pseudoplastic behaviour, which increases when $n$ decreases. In Table 1, all $n$ values obtained by Herschel-Bulkley were between 0.44 and 0.78 , indicating a pseudoplastic behaviour in these solutions with different glycerol concentrations. The fit that presented the lowest $R^{2}$ values was the Bingham model, probably because the Bingham model is a special case of Herschel-Bulkley model when $n$ is equal to unity (Newtonian fluid) (Abu-jdayil et al., 2001; Al-Malah et al., 2000; Che et al., 2008). As it can be observed from 
T a b l e 1. Parameters of the different models for the flow behaviour of potato starch solutions at different glycerol concentrations and temperatures

\begin{tabular}{|c|c|c|c|c|c|c|c|c|}
\hline $\begin{array}{l}\mathrm{G} / \mathrm{PS} \\
\text { concentration } \\
(\% \mathrm{w} / \mathrm{w})\end{array}$ & Model & $\begin{array}{c}\text { Temperature } \\
\left({ }^{\circ} \mathrm{C}\right)\end{array}$ & $\begin{array}{c}K \\
\left(\mathrm{~Pa} \mathrm{~s}^{\mathrm{n}}\right)\end{array}$ & $n$ & $\begin{array}{c}\tau_{0} \\
(\mathrm{~Pa})\end{array}$ & $\frac{\mathrm{a}}{\left(\mathrm{Pa} \mathrm{s}^{\mathrm{n}}\right)^{0.5}}$ & $\begin{array}{c}\mathrm{b} \\
(\mathrm{Pa})^{0.5}\end{array}$ & $\mathrm{R}^{2}$ \\
\hline \multirow{8}{*}{\multicolumn{2}{|c|}{ Herschel-Bulkley }} & 30 & 0.867 & 0.408 & & & & 0.999 \\
\hline & & 40 & 0.845 & 0.453 & & & & 0.999 \\
\hline & & 50 & 0.825 & 0.463 & & & & 0.996 \\
\hline & & 60 & 0.715 & 0.436 & & & & 0.999 \\
\hline & & 30 & 0.870 & 0.444 & 0.025 & & & 0.999 \\
\hline & & 40 & 0.860 & 0.494 & 0.021 & & & 0.999 \\
\hline & & 50 & 0.840 & 0.510 & 0.021 & & & 0.990 \\
\hline & & 60 & 0.800 & 0.540 & 0.026 & & & 0.999 \\
\hline \multirow[t]{8}{*}{0.1} & \multirow{4}{*}{ Bingham } & 30 & 1.478 & & 0.173 & & & 0.965 \\
\hline & & 40 & 1.428 & & 0.138 & & & 0.968 \\
\hline & & 50 & 1.391 & & 0.130 & & & 0.981 \\
\hline & & 60 & 0.981 & & 0.144 & & & 0.958 \\
\hline & \multirow{4}{*}{ Casson } & 30 & & & & 0.794 & 0.104 & 0.991 \\
\hline & & 40 & & & & 0.819 & 0.078 & 0.992 \\
\hline & & 50 & & & & 0.816 & 0.072 & 0.996 \\
\hline & & 60 & & & & 0.671 & 0.084 & 0.990 \\
\hline \multirow{8}{*}{\multicolumn{2}{|c|}{ Herschel-Bulkley }} & 30 & 0.609 & 0.330 & & & & 0.997 \\
\hline & & 40 & 0.501 & 0.335 & & & & 0.991 \\
\hline & & 50 & 0.460 & 0.325 & & & & 0.988 \\
\hline & & 60 & 0.430 & 0.320 & & & & 0.992 \\
\hline & & 30 & 0.560 & 0.450 & 0.083 & & & 0.990 \\
\hline & & 40 & 0.487 & 0.527 & 0.082 & & & 0.999 \\
\hline & & 50 & 0.447 & 0.556 & 0.087 & & & 0.999 \\
\hline & & 60 & 0.420 & 0.570 & 0.087 & & & 0.996 \\
\hline \multirow[t]{8}{*}{0.3} & \multirow{4}{*}{ Bingham } & 30 & 0.794 & & 0.185 & & & 0.918 \\
\hline & & 40 & 0.665 & & 0.149 & & & 0.966 \\
\hline & & 50 & 0.606 & & 0.142 & & & 0.970 \\
\hline & & 60 & 0.563 & & 0.136 & & & 0.960 \\
\hline & \multirow{4}{*}{ Casson } & 30 & & & & 0.533 & 0.126 & 0.972 \\
\hline & & 40 & & & & 0.490 & 0.101 & 0.995 \\
\hline & & 50 & & & & 0.462 & 0.097 & 0.997 \\
\hline & & 60 & & & & 0.442 & 0.094 & 0.993 \\
\hline
\end{tabular}

Values are expressed as mean of three experiments. 
T a b l e 1. Continuation

\begin{tabular}{|c|c|c|c|c|c|c|c|c|}
\hline $\begin{array}{l}\text { G/PS } \\
\text { concentration } \\
(\% \mathrm{w} / \mathrm{w})\end{array}$ & Model & $\begin{array}{c}\text { Temperature } \\
\left({ }^{\circ} \mathrm{C}\right)\end{array}$ & $\begin{array}{c}K \\
\left(\mathrm{~Pa} \mathrm{~s}^{\mathrm{n}}\right)\end{array}$ & $n$ & $\begin{array}{c}\tau_{0} \\
(\mathrm{~Pa})\end{array}$ & $\frac{\mathrm{a}}{\left(\mathrm{Pa} \mathrm{s}^{\mathrm{n}}\right)^{0.5}}$ & $\begin{array}{c}\mathrm{b} \\
(\mathrm{Pa})^{0.5}\end{array}$ & $\mathrm{R}^{2}$ \\
\hline \multirow{16}{*}{0.5} & \multirow{4}{*}{ Power law } & 30 & 0.441 & 0.355 & & & & 0.991 \\
\hline & & 40 & 0.395 & 0.343 & & & & 0.987 \\
\hline & & 50 & 0.312 & 0.303 & & & & 0.987 \\
\hline & & 60 & 0.296 & 0.306 & & & & 0.978 \\
\hline & \multirow{4}{*}{ Herschel-Bulkley } & 30 & 0.410 & 0.550 & 0.073 & & & 0.999 \\
\hline & & 40 & 0.365 & 0.577 & 0.077 & & & 0.999 \\
\hline & & 50 & 0.330 & 0.610 & 0.070 & & & 0.990 \\
\hline & & 60 & 0.310 & 0.778 & 0.088 & & & 0.992 \\
\hline & \multirow{4}{*}{ Bingham } & 30 & 0.477 & & 0.132 & & & 0.968 \\
\hline & & 40 & 0.423 & & 0.123 & & & 0.970 \\
\hline & & 50 & 0.403 & & 0.104 & & & 0.965 \\
\hline & & 60 & 0.385 & & 0.098 & & & 0.978 \\
\hline & \multirow{4}{*}{ Casson } & 30 & & & & 0.430 & 0.087 & 0.997 \\
\hline & & 40 & & & & 0.398 & 0.083 & 0.999 \\
\hline & & 50 & & & & 0.364 & 0.074 & 0.995 \\
\hline & & 60 & & & & 0.358 & 0.069 & 0.997 \\
\hline
\end{tabular}

Table 1, for the Herschel-Bulkley model the $K$ values decrease as a function of the increasing temperature and glycerol concentration, while $n$ values increase. The values for $\tau_{0}$, $K$ and $n$ obtained by Herschel-Bulkley equation (Table 1 ) were fitted as a function of glycerol concentration (C). It is observed that the $\tau_{0}, K$ and $n$ parameters were fitted to the second-degree polynomial models, obtaining $\mathrm{R}^{2}$ values equal to the unity.

The equations for $\tau_{0}, K$ and $n$, at every isotherm, are showed in Table 2. They were replaced into the HerschelBulkley equation, obtaining empirical equations for the prediction of shear stress and shear rate as a function of glycerol concentration. These models are shown in Table 3. High $\mathrm{R}^{2}$ values suggest that the equations can be used to describe the shear stress as a function of these two variables. Figure 3 shows a graph of the empirical equation obtained by modification of Herschel-Bulkley model at $30^{\circ} \mathrm{C}$. Che et al. (2008) proposed a similar methodology and reported an empirical model by modifying the power law in order to predict viscosity in cassava starch solutions for a concentration range between 0.2 and $1.0(\% \mathrm{w} / \mathrm{w})$.

A single equation combining the effects of temperature and glycerol concentration on shear stress in G/PS solutions is proposed. The shear stress values were fitted by multiple linear regressions to the following expression:
T a b l e 2. Fitting parameters $\tau_{0}, K$ and $n$ from the HerschelBulkley model for the potato starch solutions at different glycerol concentrations $(\mathrm{C})$ and temperatures $\left(\mathrm{R}^{2}=1.000\right)$

\begin{tabular}{|c|c|c|}
\hline $\begin{array}{l}\text { Tempe- } \\
\text { rature }\left({ }^{\circ} \mathrm{C}\right)\end{array}$ & Parameter & Equation \\
\hline \multirow{3}{*}{30} & $\tau_{0}(\mathrm{~Pa})$ & $\tau_{0}=-0.85 \mathrm{C}+0.63 \mathrm{C}-0.03$ \\
\hline & $K\left(\mathrm{~Pa} \mathrm{~s}^{\mathrm{n}}\right)$ & $K=2.00 \mathrm{C}-2.35 \mathrm{C}+1.08$ \\
\hline & $n$ & $n=1.17 \mathrm{C}-0.44 \mathrm{C}+0.48$ \\
\hline \multirow{3}{*}{40} & $\tau_{0}(\mathrm{~Pa})$ & $\tau_{0}=-0.82+0.63-0.03$ \\
\hline & $K\left(\mathrm{~Pa} \mathrm{~s}^{\mathrm{n}}\right)$ & $K=3.14 \mathrm{C}-3.12 \mathrm{C}+1.14$ \\
\hline & $n$ & $n=0.21 \mathrm{C}+0.08 \mathrm{C}+0.48$ \\
\hline \multirow{3}{*}{50} & $\tau_{0}(\mathrm{~Pa})$ & $\tau_{0}=-1.04+0.74-0.04$ \\
\hline & $K\left(\mathrm{~Pa} \mathrm{~s}^{\mathrm{n}}\right)$ & $K=3.45 \mathrm{C}-3.34 \mathrm{C}+1.40$ \\
\hline & $n$ & $n=0.1 \mathrm{C}+0.19 \mathrm{C}+0.49$ \\
\hline \multirow{3}{*}{60} & $\tau_{0}(\mathrm{~Pa})$ & $\tau_{0}=-0.75+0.60-0.03$ \\
\hline & $K\left(\mathrm{~Pa} \mathrm{~s}^{\mathrm{n}}\right)$ & $K=3.37 \mathrm{C}-3.25 \mathrm{C}+1.09$ \\
\hline & $n$ & $n=2.22 \mathrm{C}-0.74 \mathrm{C}+0.59$ \\
\hline
\end{tabular}


T a b l e 3. Empirical equation from the Herschel-Bulkley model for shear stress prediction $(\tau)$ as a function of glycerol concentration and the shear rate $(\dot{\gamma})$ at different isotherms

\begin{tabular}{|c|c|c|}
\hline $\begin{array}{l}\text { Temperature } \\
\quad\left({ }^{\circ} \mathrm{C}\right)\end{array}$ & Equation & $\mathrm{R}^{2}$ \\
\hline 30 & $\tau=\left(-0.85 \mathrm{C}^{2}+0.63 \mathrm{C}-0.03\right)+\left(2.00 \mathrm{C}^{2}-2.35 \mathrm{C}+1.08\right) \dot{\gamma}^{\left(1.17 \mathrm{C}^{2}-0.44 \mathrm{C}+0.48\right)}$ & 0.998 \\
\hline 40 & $\tau=\left(-0.82 \mathrm{C}^{2}+0.63 \mathrm{C}-0.03\right)+\left(3.14 \mathrm{C}^{2}-3.12 \mathrm{C}+1.14\right) \dot{\gamma}^{\left(0.21 \mathrm{C}^{2}+0.08 \mathrm{C}+0.48\right)}$ & 0.999 \\
\hline 50 & $\tau=\left(-1.04 \mathrm{C}^{2}+0.74 \mathrm{C}-0.04\right)+\left(3.45 \mathrm{C}^{2}-3.34 \mathrm{C}+1.40\right) \dot{\gamma}^{\left(0.10 \mathrm{C}^{2}+0.19 \mathrm{C}+0.49\right)}$ & 0.998 \\
\hline 60 & $\tau=\left(-0.75 \mathrm{C}^{2}+0.60 \mathrm{C}-0.03\right)+\left(3.37 \mathrm{C}^{2}-3.25 \mathrm{C}+1.09\right) \dot{\gamma}^{\left(2.22 \mathrm{C}^{2}-0.74 \mathrm{C}+0.59\right)}$ & 0.993 \\
\hline
\end{tabular}

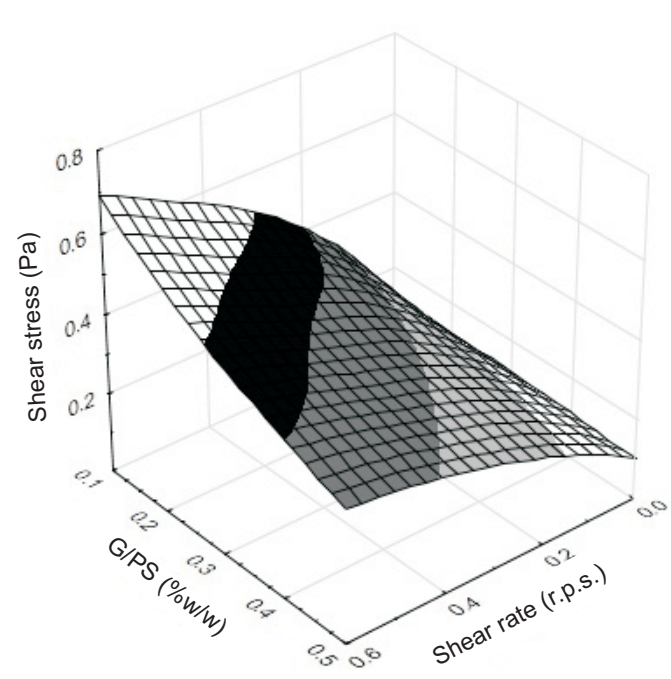

Fig. 3. Empirical model obtained from the Herschel-Bulkley equation for the prediction of shear stress as a function of shear rate and glycerol concentration in $\mathrm{G} / \mathrm{PS}$ solutions at $30^{\circ} \mathrm{C}$.

$$
\tau=\beta_{0}-\beta_{1} \mathrm{~T}-\beta_{2} \mathrm{C}+\beta_{3} \mathrm{~T}^{2} \pm \beta_{4} \mathrm{C}^{2}+\beta_{5} \mathrm{CT},
$$

where: $\mathrm{T}$ is the absolute temperature, $\beta_{0}, \beta_{1}, \beta_{2}, \beta_{3}, \beta_{4}$ and $\beta_{5}$ are constant values. $\beta_{0}$ is the mean of all shear stress values, $\beta_{1}$ and $\beta_{2}$ are related to the linear effect due to temperature and glycerol concentration, respectively, $\beta_{3}$ and $\beta_{4}$ are related to second power effects due to these same variables, finally, $\beta_{5}$ is related to the interaction effect between temperature and glycerol concentration (Ayala et al., 2013). Figure 4 shows the combined effect of temperature and glycerol concentration on the shear stress to three fixed shear rates $(0.05,0.10$ and 0.20 r.p.s. $)$. These models present values for $\mathrm{R}^{2}$ higher than those proposed for systems of the type glycerol/cassava starch solutions in which a similar equation was used (Ayala et al., 2013).
Velez and Barbosa (1997) studied the rheological properties of concentrated milk and proposed an exponential model which combined the effect of temperature and concentration for the prediction of $K$ values. We used this equation; thereby the $K$ values reported in the Table 1 obtained by fits to Herschel-Bulkley model were fitted to the equation:

$$
\begin{aligned}
& \ln K=-\beta_{0}+ \beta_{1}(1 / \mathrm{T})-\beta_{2} \mathrm{C} \rightarrow K=\mathrm{e}^{-\beta_{0}} \mathrm{e} \frac{\beta_{1}}{\beta_{2} \mathrm{CT}} \\
& \rightarrow K=\mathrm{K}_{0} \mathrm{e} \frac{E_{a}}{\mathrm{RCT}},
\end{aligned}
$$

where: $\mathrm{e}^{-\beta_{0}}$ is known as $\mathrm{K}_{0}$ and is a constant value, $E_{a}$ is the activation energy $\left(\mathrm{KJ} \mathrm{mol}^{-1}\right), \mathrm{R}$ is the universal gas constant $\left(8.314 \mathrm{~J} \mathrm{~K}^{-1} \mathrm{~mol}^{-1}\right)$ and $\mathrm{T}$ is the absolute temperature $(\mathrm{K})$. Figure 5 shows the $K$ fits to the Eq. (7). The model is shown in Fig. 5, and it can be rewritten to the form: $K=0.10 e \frac{2780.95}{\mathrm{RCT}}$, where $E_{a}$ is equal to $2.78 \mathrm{KJ} \mathrm{mol}^{-1}$; this value indicates the energy necessary to induce movement in the G/PS solutions and is lower than that reported for glycerol/cassava starch where $E_{a}$ varied between 6.14 and $6.86 \mathrm{KJ} \mathrm{mol}^{-1}$ (Ayala et al., 2013).

\section{CONCLUSIONS}

1. Experimental results show that the rheological properties of potato starch solutions are controlled by the temperature and glycerol content in the solutions within the temperature range of $20-60^{\circ} \mathrm{C}$ and glycerol/potato starch weight fraction from 0 to 0.5 . The flow curves (shear stress against shear rate) were fitted to theoretical models proposed for pseudoplastic fluids: power law, Herschel-Bulkley, Bingham, modified Bingham and Casson models.

2. It was found that the Herschel-Bulkley model is the most appropriate equation for describing the rheological behaviour of potato starch solutions as a function of glycerol 

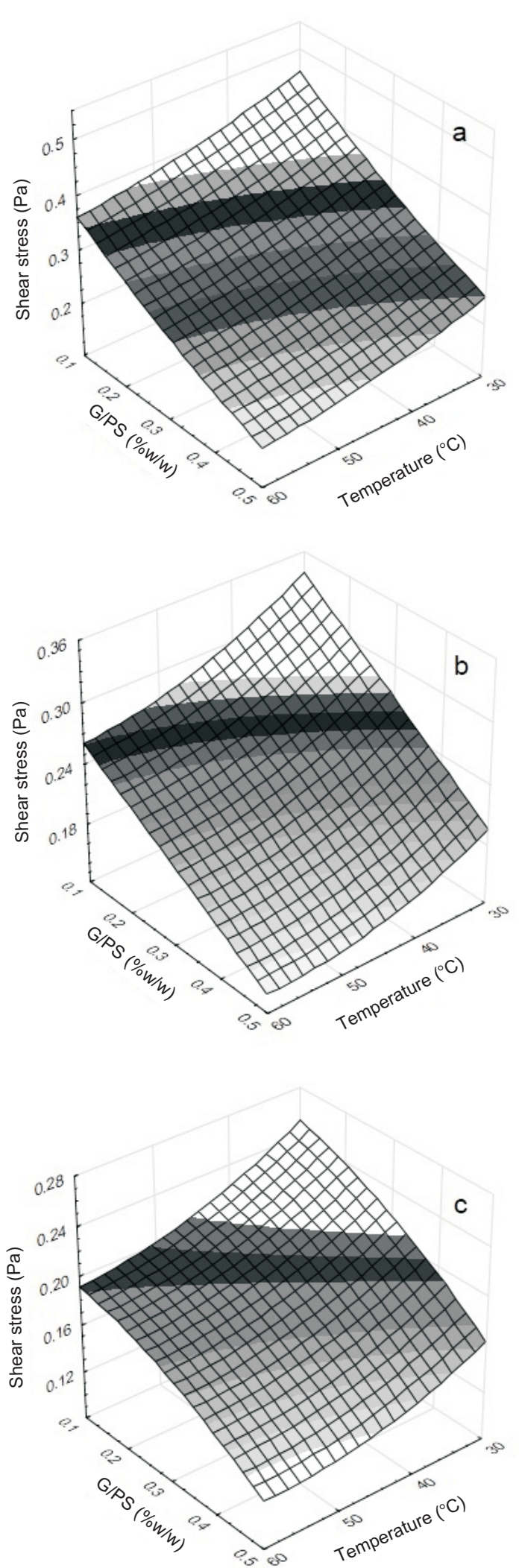

Fig. 4. Combined effects of temperature and glycerol concentration on the shear stress for G/PS solution at: $\mathrm{a}-0.20, \mathrm{~b}-0.10$, and c -0.05 r.p.s.

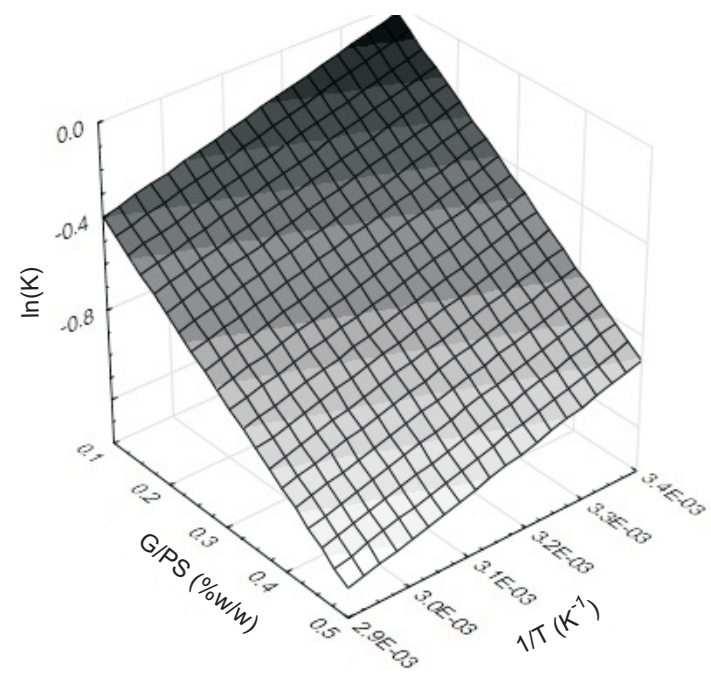

Fig. 5. Dependence of $\ln K$ on both the temperature (T) and glycerol content $(\mathrm{G} / \mathrm{PS})$ in the solutions.

concentrations and temperature. These fits revealed values for flow behaviour index between 0.44 and 0.78 , typical of pseudoplastic fluids.

3. The dependence of the consistency coefficient on both the glycerol concentration and temperature was well described by an exponential expression with an activation energy value of $2.78 \mathrm{~kJ} \mathrm{~mol}^{-1}$. The above result suggests that both the glycerol content and temperature have the effect of diluting the potato starch solutions. This study demonstrates new findings related to the rheological properties in glycerol/ potato starch solutions and could serve for future works in the simulation and design of industrial equipment.

\section{REFERENCES}

Abu-jdayil B., Azzam M.O.J., and Al-Malah K.I.M., 2001. Effect of glucose and storage time on the viscosity of wheat starch dispersions. Carbohyd. Polym., 46, 207-215.

Ahmad-Khiar A.S. and Arof A.K., 2010. Conductivity studies of starch-based polymer electrolytes. Ionics, 16, 123-129.

Al-Malah K.L., Azzam M.O.J., and Abu-jdayil B., 2000. Effect of glucose concentration on the rheological properties of wheat-starch dispersions. Food Hydrocolloid, 14, 491-496.

Alvani K., Qi X., Tester R.F., and Snape C.E., 2011. Physicochemical properties of potato starches. Food Chem., 125, 958-965.

Alvis A., Vélez C.A., Villada H.S., and Rada-Mendoza M., 2008. Physicochemical and morphological analyses of yam, cassava and potato starches and determination of their viscosity. Inf. Technol., 19, 19-28.

Ayala G., Agudelo A.C., Paz J., and Vargas R.A., 2011. Study of dc conductivity, transport mechanism, and dielectric relaxation in cassava starch membranes plasticized with glycerol. Ionics, 17, 647-652. 
Ayala G., Agudelo A., and Vargas R., 2012a. Effect of glycerol on the electrical properties and phase behavior of cassava starch biopolymers. DYNA, 79, 138-147.

Ayala G.V., Agudelo A.C.H., and Vargas R.A.Z., 2012b. Comparative study and characterization of starches isolated from unconventional tuber sources. J. Polym. Eng., 32, 531-537.

Ayala G.V., Agudelo A.C.H., and Vargas R.A.Z., 2013. Effect of glycerol concentration and temperature on the rheological properties of cassava starch solutions. J. Polym. Eng., 33, 141-148.

Bertuzzi M.A., Armada M., and Gottifredi J.C., 2007. Physicochemical characterization of starch based films. J. Food Eng., 82, 17-25.

Caicedo C.H., Ayala G., Agudelo A.C., and Vargas R.A., 2010. Effect of glycerol on the electrical properties, phase behavior and water vapor permeability in films based on potato starch. Rev. Col. Fis., 42, 439-448.

Che L.M., Li D., Wang L.J., Özkan N., Chen X.D., and Mao Z.H., 2008. Rheological properties of dilute aqueous solutions of cassava starch. Carbohyd. Polym., 74, 385-389.

Chen C.R. and Ramaswamy H.S., 1999. Rheology of tapioca starch. Food Res. Int., 32, 319-325.

Chien-Hsien Chen, Wen-Shiuh Kuo, and Lih-Shiuh Lai, 2009. Effect of surfactants on water barrier and physical properties of tapioca starch/decolorized hsian-tsao leaf gum films. Food Hydrocolloid, 23, 714-721.

Drożdż W. and Tomaszewska-Ciosk E., 2007. Rheological properties of potato starch pastes with the addition of kaolin. Polish J. Food Nutr. Sci., 57, 113-117.

Gennadios A., McHugh T.H., Weller C.L., and Krochta J.M., 1994. Edible coatings and films based on proteins. In: Edible Coatings and Films to Improve Food Quality (Eds J.M. Krochta, E.A. Baldwin, M. Nisperos-Carriedo), Technomic Press, Lancaster, PA, USA.

Grigelmo N.M., Ibarz-Ribas A., and Martín-Belloso M., 1999. Rheology of peach dietary fibre suspensions. J. Food Eng., 39, 91-99.

Juszczak L., Witczak M., and Fortuna T., 2012. Rheological behaviour of heated potato starch dispersions. Int. Agrophys., 26, 381-386.
Lagarrigue S. and Alvarez G., 2001. The rheology of starch dispersions at high temperatures and high shear rates: a review. J. Food Eng., 50, 189-202.

Iida Y., Tuziuti T., Yasui K., Towata A., and Kozuka T., 2008. Control of viscosity in starch and polysaccharide solutions with ultrasound after gelatinization. Innov. Food Sci. Emerg. Technol., 9, 140-146.

Mali S. and Grossmann M.V.E., 2003. Effects of yam films on storability and quality of fresh strawberries (Fragaria ananassa). J. Agric. Food Chem., 51, 7005-7011.

Marcotte M., Taherian A.R., Trigui M., and Ramaswamy H.S., 2001. Evaluation of rheology properties of selected salt enriched food hydrocolloids. J. Food Eng., 48, 157-167.

Nurul M.I., Azemi B.M.N., and Manan D.M.A., 1999. Rheological behaviour of sago (Metroxylon sagu) starch paste. Food Chem., 64, 501-505.

Peressini D., Bravin B., Lapasin R., Rizzotti C., and Sensidoni A., 2003. Starch-methycellulose based edible films: rheological properties of film-forming dispersions. J. Food Eng., 59, 25-32.

Perrera C., Hoover R., and Martin A.M., 1997. The effect of hydroxypropylation on the structure and physicochemical properties of native, defatted and heat-moisture treated potato starches. Food Res. Int., 30, 235-247.

Rao M.A., Okechukwu P.E., Da Silva P.M.S., and Oliveira J.C., 1997. Rheological behavior of heated starch dispersions in excess water: Role of starch granule. Carbohyd. Polym., 33, 273-283.

Sothornvit R. and Krochta J.M., 2001. Plasticizer effect on mechanical properties of $\beta$-lactoglobulin films. J. Food Eng., 50, 149-155.

Tapia-Blácido D., Mauri A.N., Menegalli F.C., Sobral P.J., and A ñon M.C., 2007. Contribution of the protein and lipid fractions to the physical, thermal and structural properties of amaranth (Amaranthus caudatus) flour films. J. Food Sci., 72, 293-300.

Tharanathan R.N., 2003. Biodegradable films and composite coatings: Past, present and future. Trends Food Sci. Technol., 14, 71-78.

Velez J.F. and Barbosa G.V., 1997. Effect of concentration and temperature on the rheology of concentrated milk. ASAE, 40, 1113-1117. 